\title{
The Effect of Dynamic Assessment in Synchronous Computer-Mediated Communication on Iranian EFL Learners' Listening Comprehension Ability at Upper-Intermediate Level
}

\author{
Davood Mashhadi Heidar ${ }^{1} \&$ Akbar Afghari ${ }^{1}$ \\ ${ }^{1}$ Department of English, Khorasgan (Isfahan) Branch, Islamic Azad University, Isfahan, Iran \\ Correspondence: Davood Mashhadi Heidar, Department of English, Khorasgan (Isfahan) Branch, Islamic Azad \\ University, Isfahan, Iran. E-mail: davoodm_tarbiatmodares@yahoo.com
}

Received: December 23, 2014 Accepted: January 26, 2015 Online Published: March 25, 2015

doi:10.5539/elt.v8n4p14 URL: http://dx.doi.org/10.5539/elt.v8n4p14

\begin{abstract}
The present paper concentrates on a web-based inquiry in the synchronous computer-mediated communication (SCMC) via Web 2.0 technologies of Talk and Write and Skype. It investigates EFL learners' socio-cognitive progress through dynamic assessment (DA), which follows Vygotsky's inclination for supportive interchange in the zone of proximal development. Sixty adult EFL learners at upper-intermediate level were randomly assigned to the control and experimental groups. The participants in the experimental group were involved in dynamic assessment in synchronous computer-mediated communication for seven weeks. The results reveal that, through interactions in the ZPD, DA in synchronous computer-mediated communication lets us explore not only the actual level of learners' listening ability but also to diagnose and assess the potential level of their listening development.
\end{abstract}

Keywords: online dynamic assessment, microgenetic development, listening comprehension, web 2.0 technologies, ZPD

\section{Introduction}

As stated by Oskoz (2005) there is plenteous publication on the application of synchronous computer-mediated communication to the EFL contexts (Beauvois, 1994, 1998; Beauvois \& Eledge, 1996; Chun, 1994; Darhower, 2002; Kelm, 1992, 1996; Kern, 1995; Warschauer, 1996, 1997). The majority of studies, however, address only instructional applications. Research dealing with assessment in this area is still in its infancy (Heather, 2003; Oscoz, 2003) and limited in scope. In particular, the number of studies investigating dynamic assessment (DA) in SCMC also seems to be rare.

Dynamic Assessment, a process-oriented/collaborative approach to guiding assessments, is grounded in the Vygotskyan codes of intervention and backing in the zone of proximal development. DA provides learners with help whenever needed all through the enactment of the two-way-negotiation assessment task. Fundamental to Vygotskyan and sociocultural methods to language learning and DA are the notions of negotiation and social learning (Lantolf, 2000; Lantolf \& Thorne, 2006). These basic modules of DA have been paid especial attention with the arrival of social webs and online communities through web 2.0 technologies that embrace an amplified weight on user-made content, documents and content sharing and two-way effort.

DA, an interactive, test-intervene-retest model of psychological and psycho-educational assessment, gives the examiner the chance to have a closer interaction with the student that will bring about learning. In DA, the assessor both gives performance-dependent response and proposes teaching in reaction to student failure to rework or boost student achievement.

The zone of proximal development (ZPD) is a fundamental concept of sociocultural theory that was pioneered by Vygotsky in the last two years of his life (1932-1934). Vygotsky was the first scholar who proposed to assess not only the actual level of learners' development but also their potential developmental level. The resolutions of educational assessment are to gauge existing attainment, envisage upcoming accomplishment, and recommend educational cures. Conventional one-point-in-time assessment (i.e., "static") or old pretest-posttest assessments have been used to achieve these objectives because they are consistent, easy to administer, and norm-referenced. Traditional assessment yields straightforward outcomes that are used to assess and pigeon-hole students. Shortly, 
traditional assessment is preoccupied with the product of student learning (or performance), whereas in DA the curiosity is in the product as well as the process of student learning.

\subsection{Synchronous Computer-Mediated Communication}

As defined by Walther (1992) Computer-mediated communication (CMC) is "synchronous or asynchronous electronic mail and computer conferencing by which senders encode text messages that are relayed from senders' computers to receivers (p. 52). CMC has also been described as "any communication patterns mediated through the computer" (Metz, 1992, p. 3). Computer-mediated communication is classified into synchronous and asynchronous modes. In synchronous communication, all members are online at the same time. In asynchronous communication there are time restraints on communication posts and replies, like emails. Walther and Burgoon (1992) argue that, "for many of us, CMC is no longer a novelty but a communication channel through which much of our business and social interaction takes place, and this transformation is expected to continue" (p. 51). They note, "CMC produces much different affective and relational patterns than do other types of communication, due to the reduction and types of cues available to participants" (p. 51). This study urges the application of SCMC, social nets and online communities through web 2.0 technologies that embrace an augmented prominence on user-produced content, documents and content sharing and concerted effort.

\subsection{Theoretical Framework}

Scholars claim that DA was at first inspired by Vygotsky's writings, in particular his thinking on the Zone of Proximal Development (e.g. Stenberg \& Grigorenko, 2002; Feuerstein, Rand, Jensen, Kaniel, \& Tzuriel, 1987). This study is conceptualized within the sociocultural theory (hereafter SCT) framework; the following section is exclusively confined to DA grounded in Vygotsky's theory.

Vygotsky considers development as an evolutionary as well as revolutionary process which is not linear and involves both progression and regression. He argued that even if development might include some regression, it still has its contribution to general movement forward (Vygotsky, 1978, 1997a), i.e. development is a process that is always pushing individuals forward even if at times it needs to step backward (Lantolf, 2007). To observe the process of listening development, this study implements an analysis anchored in the microgenetic domain. With regard to instruction, Vygotsky understands it primarily as the major source of cognitive development (Vygotsky, 1986) and in fact argues for the dialectical unity of the two processes in which instruction lays down the path for development to follow while simultaneously development opens up possibilities for further lessons (Vygotsky, 1997a).

The present study intends to apply online DA to listening instruction. That is, the study seeks to investigate the effect of online DA-based instruction on the development of listening ability in adult Iranian EFL learners at upper-intermediate level via Web 2.0 technologies of Talk and Write and Skype. In addition, the study endeavors to partially redress the existing gaps in three areas: L2 listening assessment, web 2.0 technologies, and SCMC research. What is noteworthy is that due to its reliance on mediated dialogue during the testing procedure, DA permits not only the diagnosis of specific sources of difficulty but also provides insights into the process of listening and promotes listening ability by tracking its development through microgenetic analysis, a specific qualitative method, proposed by sociocultural theory.

\section{Review of Literature}

Sociocultural theory (SCT) understands humans as "fundamentally socially organized entities" (Lantolf, 2007, p. 32) who learn to become autonomous by being social. For this reason the SCT paradigm "rejects the encapsulated and autonomous individual privileged in information processing and innatist theories" (Lantolf, 2007 , p. 32) that do not take account of the fundamental role the sociocultural environment plays in human development. Within the SCT framework, it is argued that the development of humans "is mediated by others, whether they are immediately present as in the case of parents guiding children or teachers guiding students, or displaced in time and space, as when we read texts produced by others or participate in activities such as work, organized in specific ways by a culture" (Lantolf, 2007, p. 32).

As Lantolf and Thorne (2006) point out, the SCT framework understands mediation as "the process through which humans deploy culturally constructed artifacts, concepts, and activities to regulate (i.e. gain voluntary control over and transform) the material world or their own and each other's social and mental activity" (p. 79). Thus, from the perspective of SCT, humans do not interact directly with the world and the environment in which they live instead, they use culturally constructed artifacts "created by human culture(s) over time and [...] made available to succeeding generations, which can modify these artifacts before passing them on to future generations" (Lantolf, 2000, p. 1). Culturally constructed artifacts include physical tools (e.g. technology, means 
of transportation, domestic utensils etc.) and symbolic tools (e.g. literacy, mathematics, language, etc.). Physical tools reinforce the power of humans' physical bodies whereas symbolic tools, primarily language, amplify humans' ability "to organize and communicate information and knowledge" while at the same time they "may influence, or regulate in some way, those who are the objects of [their] speaking" (Lantolf \& Thorne, 2006, p. 60). Haywood and Lidz (2007, p. 42) explain that "mediation is what good teachers and parents do when they promote high levels of mental functioning in their children [and learners]." Thus, mediation in itself is a simple concept but has tremendous consequences for individuals' intellectual development, which has its beginning in the ZPD. For this reason, the SCT-oriented DA regards the ZPD as the arena of development and places the ZPD at the core of teaching/learning as well as socialization processes.

Indeed, as Haywood and Lidz (2007, p. 74) observe, "Nowhere in the field of human endeavors is Vygotsky's concept of the zone of proximal development more relevant than in education." Vygotsky upheld that the driving motor of intellectual growth is learning which produces the ZPD and in turn activates internal processes of improvement. In his writings, Vygotsky frequently emphasized the idea that teaching would not be needed if it were not the cause of intellectual improvement (e.g. Vygotsky, 1986, 1987). He appealed that instruction is good only when it stimulates development and when it excites a variety of functions that are maturing within the ZPD (Vygotsky, 1987) and therefore, instruction should be attuned to the ZPD rather than to the actual level of development (Vygotsky, 1991). Consequently, for Vygotsky and his supporters, it has always been essential to know how instruction, a socially built occurrence, affects development; what type of instruction can be well-thought-out to be constructive instruction; and to what extent instruction may stimulate improvement.

\subsection{Interventionist and Interactionist DA}

L2 research distinguishes two types of DA, i.e. Interventionist and Interactionist (Lantolf \& Poehner, 2004). Lantolf and Poehner (2004) characterize the interventionist approach to DA as a more formal and standardized approach, concerned with psychometric properties of test procedures. In their view, interventionist DA encompasses studies that devise and implement a pre-determined list of hints followed rigidly during assessment activities in order to generate a weighted score. Interventionist DA finds its origins in Vygotsky's early work on the use of IQ testing in school settings that include "quantitative interpretation of the ZPD as a difference score" (Poehner \& Lantolf, 2005). According to Poehner and Lantolf (2005), the interventionist DA is currently applied in two formats: an 'item-by-item' approach (or layer-cake format) during which mediation is based on a prefabricated menu of hints and a pretest-treatment-posttest (or sandwich format) experimental approach.

The interactionist approach to DA implies mediation emerging from interaction between examiner and examinee. This type of DA represents dialogic or cooperative interaction (Poehner, 2005), in which the examiner immediately reacts to the examinee's needs, and learners are allowed to pose questions and receive immediate feedback. During interactionist DA sessions, leading questions, hints or prompts are not planned in advance and teacher-learner interactions are fine-tuned to the learner's ZPD.

\subsection{Previous Studies on DA}

Even though theoretical framework of dynamic assessment was suggested by Vygotsky, he did not offer any methodological procedures for its use in real educational situations. There is a strong research literature on dynamic assessment in general education and psychology, however, the method is rather nameless or at best new in second/foreign language studies.

Amongst the restricted number of experimental studies is Grigorenko, Sternberg, and Ehrman's (2000) in which a learning theory called CANAL-F (Cognitive Ability for Novelty in Acquisition of Language (Foreign) was developed. Consistent with this theory, learning including foreign language learning is realized as the ability to deal with newness and ambiguity (p. 392). According to this theory the researchers formed a formal test that measured the ability of learners to deal with new problems. They term this test as CANAL-FT. It has different subtests including morphology, semantics and syntax as well. During the test advised language was introduced to the learners along with some examples of it. The students were then asked to do some tasks in that language. At each stage of the test new information about that language was delivered to the learners and their ability in applying this information to carry on the tasks was measured. Although any kind of mediation or guidance is not given throughout the test, the researchers accept as true that their study is an example of dynamic assessment because it unswervingly measures the amount of learners' language learning during the assessment process.

Nassaji and Cumming (2000) meant to investigate structures of the ZPD in language teaching and learning. They examined 95 exchanges in interactive dialogue journals written over 10 months between a 6-year-old Farsi speaker starting to learn English and his Canadian teacher and disclosed how the teacher and student created and continued a long term written conversation including elaborate patterns of balancing, asymmetrical scaffolding. 
They accentuate the worth of analyzing language learning and teaching as inherently amalgamated, cooperative phenomena. Using an analytic outline that highpoints the functional dimensions of interpersonal communication, they displayed different patterns in the written exchanges between the teacher and student that sustained, in a complementary, dynamic, and developing manner over nearly a year, conditions for an ESL student's learning English literacy, scaffolded by his teacher.

Lantolf and Aljaafreh (1995) observed the interaction between adult ESL learners and a teacher. Learners developed in the ZPD through developmentally sensitive aid in teaching sessions. The occurrence of a ZPD through pair-work caused performance at a higher level of capability for both students because a learner achieves above his/her level of individual ability in the ZPD with the help of the peer and as the learner acts with growing independence development follows.

One of the renowned studies in DA is Anton's. Anton (2003) in her study used a dynamic assessment procedure for placement of L2 Spanish undergraduate students. She clarifies that dynamic assessment is more fitting for placement purposes because it sheds light on students' developing abilities rather than focusing exclusively on developed ones which is done by non-dynamic assessment. She is certain of the fact that using dynamic assessment procedures makes the placement become more precise since a thorough portrait of the abilities is offered. So chief concealed differences among students become obvious which is a proof of the validity of dynamic assessment.

\section{Method}

\subsection{Participants}

The participants, their age ranging between 25 and 32, were randomly selected from among Iranian adult EFL learners at an English language institute in Tehran, Iran. Sixty upper-intermediate participants took part in this study. In order to control the participants' proficiency levels, an OPT and a demographic information questionnaire were administered. In this study, two groups of participants were involved, control and experimental groups. The participants were randomly assigned to the control and the experimental groups, that is, thirty participants were randomly assigned to the control group, thirty to the experimental group. Participants in the control group received traditional instruction, but the experimental group received online intervention-mediated instruction via web 2.0 technologies of Talk and Write and Skype.

\subsection{Dialogs as Listening Materials}

In order to provide listening materials that would correspond to the study requirements, it was decided to collect audio dialogs by English native speakers. L2 research regards dialogs as a valuable genre to be used in listening instruction because they represent "one of the few natural conversations conducted for the benefit of non-participants" (Buck, 2003, p. 167). In this respect, the dialogs allow teachers to provide situations in which learners can pick up conversational rules and learn how to carry out conversational interactions.

\subsection{The Design of the Study}

The present investigation has a pre-test/enrichment program/post-test design. First, the learners carry out the recall independently (e.g. NDA sessions) and then they repeat it but with mediation (e.g. DA sessions). In effect, during DA and NDA sessions there are two opportunities to assess microgenetic listening development: independent listening performance and mediated listening performance. The quantitative analysis of independent recall of the propositional content of the selected texts and the qualitative analysis of the mediational process through which the students and the mediator negotiate understanding of the relevant texts are carried out. Through this process the mediator is able to formulate fine-grained diagnosis of learner abilities, including most importantly, their problem areas with regard to listening comprehension. On the basis of the diagnosis obtained through mediated interaction, the enrichment session is organized. The design of the study is outlined in Table 1. 
Table 1. Experiment design: Assessment and enrichment program sessions

\begin{tabular}{|c|c|c|c|}
\hline Assessment & Task description & Materials & Mediation offered \\
\hline Pre-test: NDA 1 & $\begin{array}{l}\text { 1) Listening to a text in L2; } \\
\text { 2) Independent oral text recall in } L 2\end{array}$ & $\begin{array}{l}\text { Text 1: An authentic } \\
\text { segment (audio format) }\end{array}$ & None \\
\hline Pre-test: DA 1 & $\begin{array}{l}\text { 1) Listening to a text in } \mathrm{L} 2 \text {; } \\
\text { 2) Independent oral text recall in } \mathrm{L} 2 \\
\text { 3) Oral text recall in L2 after } \\
\text { mediation }\end{array}$ & $\begin{array}{l}\text { Text 2: An authentic } \\
\text { segment (audio format) }\end{array}$ & $\begin{array}{l}\text { Flexible interaction } \\
\text { with the mediator }\end{array}$ \\
\hline $\begin{array}{l}\text { Enrichment program: } 4 \\
\text { weeks (two tutoring } \\
\text { sessions per week) }\end{array}$ & & & $\begin{array}{l}\text { Flexible interaction } \\
\text { with the mediator }\end{array}$ \\
\hline Post-test: NDA2 & $\begin{array}{l}\text { 1) Listening to a text in } L 2 \text {; } \\
\text { 2) Independent oral text recall in } L 2\end{array}$ & $\begin{array}{l}\text { Text 3: An authentic } \\
\text { segment (audio format) }\end{array}$ & None \\
\hline Post-test: DA 2 & $\begin{array}{l}\text { 1) Listening to a text in } L 2 \text {; } \\
\text { 2) Independent oral text recall in } L 2 \\
\text { 3) Oral text recall in L2 after } \\
\text { mediation }\end{array}$ & $\begin{array}{l}\text { Text 4: An authentic } \\
\text { segment (audio format) }\end{array}$ & $\begin{array}{l}\text { Flexible interaction } \\
\text { with the mediator }\end{array}$ \\
\hline
\end{tabular}

Adapted from Poehner (2005).

Mediation or Flexible interactions involved researcher's leading questions, implicit and explicit hints, prompts, and explanations.

\subsection{Text Comprehension Measurement}

To measure comprehension, this study implemented immediate oral text recalls. The participants were asked to recall in English as much as they could of what they were listening to with a special focus on the main ideas of the text. Then, the researcher identified the relationship between propositions (idea units) of the original text and the texts of participants' recall. In this fashion, propositions from students' immediate oral recalls that were closely related to propositions from the original text were counted and scored against the list of idea units designated independently by the raters before the study. The number of recalled idea units was viewed as evidence of text comprehension.

\subsection{Oral Recalls Scoring}

The oral recalls of the learners were analyzed by the researcher for the total number of idea units (IU) accurately produced and subsequently for the number of main IUs, supporting IUs and details recalled. The recalls were scored against the list of IUs and only the information explicitly stated in the aural text was counted.

\subsection{Data Analysis}

To compare participants' scores on the pre-test and post-test a series of paired sample t-tests was run. An independent-samples t-test was also conducted to compare the posttests of the control and experimental groups.

\section{Results}

The descriptive analysis of the data for different groups of the study has been summarized below. Table 2 summarizes the descriptive analysis of the data of before-enrichment and after-enrichment scores for the experimental group:

Table 2. Descriptive analysis of the data for experimental group (paired sample statistics)

\begin{tabular}{llllll}
\hline & Mean & $\mathrm{N}$ & Std. Deviation & Std. Error Mean \\
\hline Pair 1 & $\begin{array}{l}\text { Upper-intermediates DA } \\
\text { Before Enrichment }\end{array}$ & 20.30 & 30 & 3.816 & .697 \\
$\begin{array}{l}\text { Upper-intermediates DA } \\
\text { After Enrichment }\end{array}$ & 27.17 & 30 & 5.389 & .984 \\
\hline
\end{tabular}


As Table 2 indicates, the mean for upper-intermediate participants before enrichment is 20.30 ( $\bar{X}=20.30$ ) while the mean for upper-intermediate participants after enrichment is $27.17(\bar{X}=27.17)$. The higher standard deviation of after-enrichment group indicates more variety among the scores from the mean. Finally, the amount of standard error is lower in the before-enrichment group scores.

Table 3 summarizes the descriptive analysis of the data of pre-test and post-test scores for the control group:

Table 3. Descriptive analysis of the data for control group (paired samples statistics)

\begin{tabular}{llllll}
\hline & Mean & $\mathrm{N}$ & Std. Deviation & Std. Error Mean \\
\hline Pair 1 & $\begin{array}{l}\text { Control Group } \\
\text { NDA Pre-test }\end{array}$ & 21.03 & 30 & 5.666 & 1.034 \\
$\begin{array}{c}\text { Control Group } \\
\text { NDA Post-test }\end{array}$ & 21.20 & 30 & 5.598 & 1.022 \\
\hline
\end{tabular}

As Table 3 indicates, the mean of participants in the control group for pre-test is 21.03 ( $\bar{X}=21.03$ ) while the mean of participants in the control group for the post-test is $21.20(\bar{X}=21.20)$. The higher standard deviation of pre-test group indicates more variety among the scores from the mean. Finally, the amount of standard error is lower in the post-test group scores.

\subsection{Inferential Analysis of the Data}

This study investigated the extent to which Iranian EFL learners' listening ability could enhance as a result of online dynamic assessment through web 2.0 technologies of Talk and Write and Skype. The inferential analysis of the data is summarized below.

Table 4 summarizes the inferential analysis of the data of before-enrichment and after-enrichment scores for the experimental group:

Table 4. Paired-sample $t$ value for experimental group

\begin{tabular}{lllllll}
\hline \multicolumn{7}{c}{ Paired Differences } \\
\hline Pair 1 & Mean & $\begin{array}{l}\text { Standard } \\
\text { Deviation }\end{array}$ & $\begin{array}{l}\text { Std. Error } \\
\text { Mean }\end{array}$ & $\mathbf{t}$ & df & Sig. (2-tailed) \\
\hline $\begin{array}{l}\text { Upper-intermediates DA } \\
\text { Before Enrichment- }\end{array}$ & 6.867 & 3.137 & .573 & $\mathbf{1 1 . 9 8 7}$ & 29 & .000 \\
$\begin{array}{l}\text { Upper intermediates DA } \\
\text { After Enrichment }\end{array}$ & & & & & & \\
\hline
\end{tabular}

As Table 4 indicates, the observed $t$ value for upper-intermediate participants before and after enrichment is 11.987 (tobs $=11.987$ ) which is much higher than the critical $t$ value (tcrit $=2.045$ with the level of significance of 0.05 and degree of freedom of $29, \mathrm{df}=29$ ). This rejected the first null hypothesis of the study which meant that the enhancement of Iranian EFL learners' listening ability was to a large degree affected by online dynamic assessment through web 2.0 technologies of Talk and Write and Skype.

Table 5 summarizes the inferential analysis of the data of pre-test and post-test scores for the control group:

Table 5. Paired-sample t value for the control group

\begin{tabular}{lllllll}
\hline \multicolumn{7}{c}{ Paired Differences } \\
\hline Pair 1 & Mean & $\begin{array}{l}\text { Standard } \\
\text { Deviation }\end{array}$ & $\begin{array}{l}\text { Std. Error } \\
\text { Mean }\end{array}$ & t & df & Sig. (2-tailed) \\
\hline $\begin{array}{llllll}\text { Control Group } \\
\text { NDA Pre-test- }\end{array}$ & & & & & \\
Control Group & .167 & .531 & .097 & $\mathbf{1 . 7 2 0}$ & 29 & .096 \\
NDA Post-test & & & & & & \\
\hline
\end{tabular}


As Table 5 indicates, the observed t value of participants in the control group for the pre-test and post-test is 1.720 (tobs $=1.720$ ) which is lower than the critical $t$ value ( $t$ crit $=2.045$ with the level of significance of 0.05 and degree of freedom of 29 , df $=29$ ). This illustrated that participants in the control group did not show improvement. As a result, it can be concluded that participants' listening ability in the experimental group was affected by online dynamic assessment through web 2.0 technologies of Talk and Write and Skype.

Table 6 summarizes the inferential analysis of the data of posttests of the control and experimental groups:

Table 6. Independent samples test for control and experimental groups

\begin{tabular}{lllllllll}
\hline & \multicolumn{3}{c}{ Levene's Test for Equality of Variances } & \multicolumn{2}{c}{ t-test for Equality of Means } \\
\cline { 2 - 8 } & $\mathrm{F}$ & $\mathrm{Sig}$. & $\mathrm{t}$ & $\mathrm{df}$ & Sig.(2-tailed) & $\begin{array}{l}\text { Mean } \\
\text { Difference }\end{array}$ & $\begin{array}{l}\text { Std. } \\
\text { Difference }\end{array}$ \\
\hline PT & $\begin{array}{l}\text { Equal variances } \\
\text { Assumed }\end{array}$ & .168 & .532 & 3.763 & 58 & $\mathbf{. 0 0 2}$ & 5.970 & 1.406 \\
$\begin{array}{l}\text { Equal variances } \\
\text { not Assumed }\end{array}$ & & & 3.763 & 57.991 & $\mathbf{. 0 0 2}$ & 5.970 & 1.406 \\
\hline
\end{tabular}

An independent-samples t-test was conducted to compare the posttests of the control and experimental groups. The sig. value for Levene's test for equality of variances was more than .05 which meant that equal variances were assumed. The value in the sig. (2-tailed) column was .002 which meant there was a significant difference in scores for the control group $(\mathrm{M}=21.20, \mathrm{SD}=5.598)$ and experimental group $(\mathrm{M}=27.17, \mathrm{SD}=5.389)$. As indicated in table (4.5), the t-value between the posttests of the experimental and control groups was also calculated. The observed $\mathrm{t}$ was calculated as to be $3.763\left(\mathrm{t}_{\mathrm{obs}}=3.763\right)$ and the degree of freedom was $58(\mathrm{df}=$ 58). The $t$-observed value, 3.763, at 58 degrees of freedom is higher than the critical value of $t$, that is, 2.000. It can again be concluded that there was a significant difference between the means of the experimental and control groups.

\section{Discussion and Conclusion}

The present research provides a close analysis of L2 listening processes and diagnostics associated with the development of listening ability among Iranian EFL learners at upper-intermediate level. To diagnose and explore L2 listening development, the study applied theoretical and methodological principles of DA, informed by Vygotsky's sociocultural theory of cognitive development. Following DA methodology that prescribes mediation during an assessment procedure, the learners were engaged in a learning activity oriented towards their ZPD. This is crucial since SCT-based DA is unthinkable and improbable without a ZPD-anchored learning activity, as opposed to other forms of assessments that include the provision of immediate feedback (e.g. formative assessment). The results of the study show that learners' ability to understand authentic spoken English independently was quite limited. However, when engaged in mediational dialogue via web 2.0 technologies of Talk and Write and Skype, the learners showcased their responsiveness to assistance, offered explicitly or implicitly, depending on the severity of problems experienced, and were able to achieve a better understanding of the texts. In the context of SCT, this means that the learners were engaged in an activity, i.e. listening to L2 authentic discourse, which was within their ZPD.

As Lantolf (2007) suggests SCT understands humans as "fundamentally socially organized entities" who learn to become autonomous by being social. For this reason the SCT paradigm "rejects the encapsulated and autonomous individual privileged in information processing and innatist theories" (Lantolf, 2007, p. 32) that do not take account of the fundamental role the sociocultural environment plays in human development. Within the SCT framework, it is argued that the development of humans "is mediated by others, whether they are immediately present as in the case of parents guiding children or teachers guiding students, or displaced in time and space, as when we read texts produced by others or participate in activities such as work, organized in specific ways by a culture" (Lantolf, 2007: 32). Dynamic Assessment which is a process-oriented, interactive approach to assessment is grounded on the Vygotskyan principles of mediation and assistance in the zone of proximal development. DA offers learners support every time looked for throughout the performance of the assessment task through joint negotiation. At the core of Vygotskyan and sociocultural approaches to language learning and DA are the notions of mediation and social learning (Lantolf, 2000; Lantolf \& Thorne, 2006). These main constituents of DA have taken on unusual prominence with the coming of social webs and online communities through web 2.0 technologies that embrace an amplified emphasis on user-created content, data and 
content sharing and cooperative effort.

As discussed by Furstenberg et al. (2001) moves in pedagogy from an individual orientation to a collaborative one as well as from a product-oriented medium to a process-oriented one gives rise to the imperative for new evaluation tools and a new research agenda that are compatible with the goals and context of instruction. DA, focusing on the process rather than on the product, presents itself as an alternative approach to assess students' performance in SCMC. Donato (1994) and Ohta (2000) have shown that the ZPD happens not only in collaboration with an expert, but also in peer interactions. SCMC also generates an environment in which learners become leaders for one another in a process of scaffolding in the ZPD (Beauvois, 1997). The collaborative nature of SCMC reduces some of the possible problems with the use of DA in the classroom, such as time necessary to conduct the assessment (Antón, 2003). It is also possible to revisit students' transcripts to afford a more truthful diagnosis of learners' potential level of development.

As Furstenberg et al. (2001) claim, assessment in SCMC seems a difficult task to undertake because students' work is situated within a new medium-network-based communication, within a new learning environment-collaborative rather than individual, and it is process rather than product-oriented. The results of this study indicate that the pedagogical shifts (from individual to collaborative and from product to process) demand new evaluation tools and new research agendas that are both congruent to the goals and the context. Dynamic assessment, which focuses on the learning process rather than on the product, may serve as a useful framework for assessing students' performance in SCMC. Rather than focus on what learners know and can do at a given moment in time as measured by their performance on a set of tasks, DA focuses on learners' potential development.

From the perspective of SCT, the results can be interpreted as follows. While the learners cannot yet fully understand an authentic text independently and, therefore, still require mediation, their responsiveness to assistance demonstrates that their capacity to comprehend such texts is in the process of ripening. In other words, it is argued here that the learners are ready to respond effectively to appropriate instruction, but the instruction must take into account their developmental differences. Thus, even though the learners were enrolled in the same level course, they were clearly not at the same level of ability with regard to comprehending authentic spoken English. This crucial fact, along with knowledge of the source of the problems unique to each learner was only brought to light as a result of online DA-based interactions.

The SCT framework reserves a privileged place for mediation as a means of understanding and promoting the process of development. Haywood and Lidz (2007) claim that not all social environments provide adequate mediation needed for the effective promotion of cognitive processes, which is why they especially acknowledge mediation offered in learning situations. With regard to the effectiveness of mediation in educational settings, Lantolf and Thorne (2006, p. 356) caution that "it cannot be offered in a haphazard, hit-or-miss fashion". Following the SCT tradition in DA research, they insist that mediation should account for individuals' actual level of development as well as being continuously adjusted to the dynamics of learners' ZPD, i.e. their potential for future development. Additionally, mediation should be regularly re-adjusted to the changes and gains in the learners' development.

\section{References}

Alderson, J. C. (2005). Diagnosing foreign language proficiency. The interface between learning and assessment. London, Continuum.

Antón, M. (2003, March). Dynamic assessment of advanced foreign language learners. Paper presented at the meeting of the American Association of Applied Linguistics, Washington, DC.

Beauvois, M. (1994). E-talk: Attitudes and motivation in computer-assisted classroom discussion. Computers and the Humanities, 28, 177-190. http://dx.doi.org/10.1007/BF01830738

Beauvois, M. (1998). Conversations in slow motion: Computer-mediated communication in the foreign language classroom. The Canadian Modern Language Review, 54, 198-217.

Beauvois, M., \& Eledge, J. (1996). Personality types and megabytes: Student attitudes toward computer-mediated communication (CMC) in the language classroom. CALICO Journal, 13(3), 27-45. http://dx.doi.org/10.11139/cj.12.2\%26

Buck, G. (2003). Assessing Listening. Cambridge: Cambridge University Press.

Chun, D. (1994). Using computer networking to facilitate the acquisition of interactive competence. System, 22, $17-31$. 
Darhower, M. (2002). Interactional features of synchronous computer-mediated communication in the intermediate L2 class: A sociocultural case study. CALICO Journal, 19(2), 249-277. http://dx.doi.org/10.1016/S0346-251X(02)00071-4

Feuerstein, R., Rand, Y., Jensen, M. R., Kaniel, S., \& Tzuriel, D. (1987). Dynamic Assessment: An Interactional Approach to Evaluating Learning Potential. New York: The Guilford Press.

Field, J. (2008). Listening in the language classroom. Cambridge: Cambridge University Press.

Flowerdew, J., \& Miller, L. (2005). Second Language Listening: Theory and Practice. Cambridge: Cambridge University Press.

Grigorenko, E. L., Sternberg, R. J., \& Ehrman, M. E. (2000). A theory-based approach to the measurement of foreign language learning ability: The CANAL-FT theory and test. The Modern Language Journal, 84, 390-405. http://dx.doi.org/10.1111/0026-7902.00076

Haywood, H. C., \& Lidz, C. S. (2007). Dynamic assessment in practice: Clinical and educational applications. Cambridge: Cambridge University Press.

Heather, J. (2003). The validity of computer-mediated communicative language tests (Unpublished doctoral dissertation). The University of Arizona.

Kelm, O. (1992). The use of synchronous computer networks in second language instruction: A preliminary report. Foreign Language Annals, 25, 441-445. http://dx.doi.org/10.1111/j.1944-9720.1992.tb01127

Kelm, O. (1996). The application of computer network in foreign language education: Focusing on principles of second language acquisition. In M. Warschauer (Ed.), Telecollaboration in foreign language learning (pp. 19-28). Manoa, HI: University of Hawai'i Press.

Kern, R. (1995). Restructuring classroom interaction with network computers: Effects on quantity and characteristics of language production. Modern Language Journal, 79, 457-476. http://dx.doi.org/10.1111/j.1540-4781.1995.tb05445

Lantolf, J. (2000). Introducing sociocultural theory. In J. P. Lantolf (Ed.), Sociocultural theory and second language learning (pp. 1-26). Oxford: Oxford University Press.

Lantolf, J. P. (2007). Sociocultural source of thinking and its relevance for second language acquisition. Bilingualism: Language and Cognition, 10(1), 31-33. http://dx.doi.org/10.1017/S1366728906002768.31

Lantolf, J. P., \& Aljaafreh, A. (1995). Second language learning in the Zone of Proximal Development: A revolutionary experience. International Journal of Educational Research, 23, 619-632. http://dx.doi.org/10.1016/0883-0355(96)80441-1

Lantolf, J. P., \& Poehner, M. E. (2004). Dynamic assessment of L2 development: Bringing the past into the future. Journal of Applied Linguistics, l(2), 49-72. http:// dx.doi.org/10.1558/japl.1.1.49.55872

Lantolf, J. P., \& Thorne, S. (2006). Sociocultural Theory and the Genesis of Second Language Development. Oxford: Oxford University Press.

Metz, J. M. (1992). Computer mediated-communication: Perceptions of a new context. Paper presented at the Speech Communication Association annual conference, Chicago, IL.

Nassaji, H., \& Cumming, A. (2000). What is in a ZPD? A case study of a young ESL student and teacher interacting through dialogue journals. Language TeachingResearch, 4(2), 95-121.

Nunan, D. (1997). Listening in Language Learning. The Language Teacher, 21(9), 47-51.

Omaggio-Hadley, A. (2000). Teaching Language in Context (2nd ed.). Heinle.

Oscoz, A. (2003). Jigsaw and free discussion in synchronous computer-mediated communication (Unpublished doctoral dissertation). University of Iowa.

Oscoz, A. (2005). Students' Dynamic Assessment via Online Chat. CALICO Journal, 22(3), 513-536. http://dx.doi.org/10.11139/cj.22.3. 513-536

Poehner, M. E. (2005). Dynamic assessment of oral proficiency among advanced L2 learners of French (Unpublished dissertation). Pennsylvania State University, University Park.

Poehner, M., \& Lantolf, J. (2004). Dynamic assessment in the language classroom. CALPER professional development document (CPDD) 0411. The PennsylvaniaState University, Center for Advanced Language Proficiency, Education and Research. 
Rost, M. (2002). Teaching and Researching Listening. Longman: Pearson Education.

Rubin, J. (1994). A review of second language listening comprehension research. The Modern Language Journal, 78(2), 199-211. http://dx.doi.org/10.1111/j.1540-4781.1994.tb02034.x

Sternberg, R. J., \& Grigorenko, E. L. (2002). Dynamic testing: The nature and measurement of learning potential. Cambridge: Cambridge University Press.

Ur, P. (1984). Teaching Listening Comprehension. Cambridge: Cambridge University Press.

Vandergrift, L. (1998). Successful and less successful listeners in French: What are the strategy differences? The French Review, 71(3), 370-395.

Vandergrift, L. (2007). Recent developments in second and foreign language listening comprehension research. Language Teaching, 40, 191-210. http://dx.doi.org/10.1017/S0261444807004338

Vygotsky, L. S. (1978). Mind in society. The development of higher psychological processes. Cambridge, MAL: Harvard University Press.

Vygotsky, L. S. (1986). Thought and Language. Cambridge, MA: MIT Press.

Vygotsky, L. S. (1987). Thinking and Speech. In R. W. Rieber, \& A. S. Carton (Eds.), Problems of General Psychology (Vol. 1). New York: Plenum.

Vygotsky, L. S. (1991). Pedagogicheskayapsykhologia [Educational Psychology]. Moskva: Pedagogika.

Vygotsky, L. S. (1997a). The History of the Development of Higher Mental Functions. In R. W. Rieber (Ed.), The History of the Development of Higher Mental Functions (Vol. 4). New York: Plenum.

Walther, J. B. (1992). Interpersonal effects in computer-mediated interaction: A relational perspective. Communication Research, 19, 52-90. http://dx.doi.org/10.1177/009365092019001003

Walther, J. B., \& Burgoon, J. K. (1992). Relational communication in computer mediated interaction. Human Communication Research, 19, 50-88. http://dx.doi.org/10.1111/j.1468-2958.1992.tb00295

Warschauer, M. (1996). Comparing face-to-face and electronic discussion in the second language classroom. CALICO Journal, 13(2), 7-26. http://dx.doi.org/10.1111/j.1944-9720.1994.tb01225

Warschauer, M. (1997). Computer-mediated collaborative learning: Theory and practice. Modern Language Journal, 81, 470-481. http://dx.doi.org/10.4018/ 978-1-59140-174-2.ch008

\section{Copyrights}

Copyright for this article is retained by the author(s), with first publication rights granted to the journal.

This is an open-access article distributed under the terms and conditions of the Creative Commons Attribution license (http://creativecommons.org/licenses/by/3.0/). 